\title{
ACTAS DEL III SEMINARIO SOBRE RELACIONES JURÍDICAS INTERNACIONALES: EL RETO DE LA INTEGRACIÓN DE LOS INMIGRANTES Y SU REPERCUSIÓN EN LA UNIÓN EUROPEA
}

\author{
Y actividades realizadas en el Curso de Verano titulado "Status jurídico de los \\ extranjeros en la UE y su implicación en las políticas de integración y en el \\ seno del IV Seminario sobre Relaciones Jurídicas Internacionales: avances y \\ retrocesos en la política migratoria europea
}

\author{
Profa. Dra. Aurelia Álvarez Rodríguez \\ Profesora TU, acreditada Catedrática, de Derecho internacional privado \\ Universidad de León \\ Prof. D. David Carrizo Aguado \\ Profesor ayudante de Derecho internacional privado \\ Universidad de León
}

\section{INTRODUCCIÓN Y DATOS A RESALTAR}

La celebración de estas jornadas sobre la incidencia de los desplazamientos de de personas de carácter transfronterizo, concretamente el III Seminario sobre Relaciones Jurídicas Internacionales celebrado en la Facultad de Derecho de la Universidad de León, los días 14 y 27 de octubre de 2015 se centró en "El reto de la integración de los inmigrantes y su repercusión en la UE"; y el IV Seminario sobre Relaciones Jurídicas Internacionales: Avances y retrocesos en la política migratoria europea, impartido en la Facultad de Derecho de la Universidad de León los días 27 y 28 de septiembre de 2016, nos permite apuntar que se ha conseguido consolidar y dar continuidad a las reuniones celebradas al Seminario anual sobre Relaciones Jurídicas Internacionales.

Cabe recordar que las reuniones anuales comenzaron su andadura con el I Seminario sobre Relaciones Jurídicas Internacionales: Familia e Interculturalidad. El Grupo (INNAIN) de la Universidad de León contó con la colaboración de cuatro universidades extranjeras: Université Abdelmalek Essaadi (Marruecos), Universidad Autónoma del Estado de México (México), Università della Calabria (Italia), Universidad de Cartagena (Colombia), impartido en la Facultad de Derecho de la Universidad de León, los días 6 y 13 de noviembre de 2013. Contó con 15 ponentes (siete españoles, ocho extranjeros) y fue seguido - presencialmente y a través de la plataforma Moodle- por 526 alumnos inscritos dentro y fuera de España. Y, al II 
Seminario sobre Relaciones Jurídicas Internacionales: Inmigración, Educación e Interculturalidad, impartido en la Escuela de Ingenierías Industrial e Informática de la Universidad de León, los días 13 y 20 de noviembre de 2014.

La directora del área de Derecho internacional privado de la Universidad de León, Aurelia Álvarez Rodríguez, es la responsable tanto del Grupo de Investigación relativo a la regulación de los flujos migratorios (INNAIN) como del Grupo Innovación Docente de la ULE sobre "Inmigración, nacionalidad e interculturalidad" (GID-INI). De los trabajos conjuntos de todos los miembros que constituyen los dos grupos señalados han llevado a cabo cuatro ediciones del Seminario sobre Relaciones Jurídicas Internacionales y un Curso de Verano.

No cabe duda que lo que se pretende es dar a conocer una visión general de la política migratoria europea y española desde una perspectiva multidisciplinar de carácter teórico-práctica. Entre sus objetivos fundamentales destacan dos aspectos: distinguir claramente los diferentes regímenes normativos según el colectivo y el origen de las disposiciones legales; además de divulgar no solo las normas sino también la interpretación de las mismas, analizando la jurisprudencia más relevante, en materias tales como: matrimonios poligámicos, diálogo intercultural, sustracción de menores, expulsiones forzadas, trata de seres humanos, integración de inmigrantes, entre otros.

\section{ACTAS DEL III SEMINARIO SOBRE RELACIONES JURÍDICAS INTERNACIONALES: EL RETO DE LA INTEGRACIÓN DE LOS INMIGRANTES Y SU REPERCUSIÓN EN LA UNIÓN EUROPEA}

Este encuentro se inició con unas palabras de bienvenida por parte del Dr. Juan José Fernández Domínguez (Decano de la Facultad de Derecho) y Dr. José Luís Chamosa González (Vicerrector de Relaciones Internacionales y Relaciones Institucionales de la ULE).

En la primera jornada, el día 14 de octubre tras la presentación por parte de las autoridades académicas, se comenzó con un trabajo intenso que contó con una Ponencia general marco y una mesa redonda.

TÍTULO PONENCIA: "Análisis de los flujos migratorios procedentes de África" Ponente: D. Jesús García Luengos, Investigador del Grupo de Estudios Africanos (GEA) de la UAM. Evaluador de proyectos de la AECID

La ponencia aborda algunas claves de una dimensión que normalmente permanece oculta a nuestra mirada y conocimiento, y que los medios de comunicación abordan de forma superficial y esporádica. Esta dimensión hace referencia a las condiciones de vida de los migrantes africanos, sus causas, y a aquellos actores -fundamentalmente políticos y económicos, tanto africanos como externos- que desempeñan un papel clave en esta cuestión. El análisis se centra en la región de África Subsahariana y, sobre todo, en los países ricos en recursos naturales (en torno a 30 
países de un total de 49). Se estima que un tercio de las reservas minerales del mundo se encuentran en dicha región y en torno a un $10 \%$ de las reservas de petróleo.

La premisa de partida es que para un conocimiento completo de todo el fenómeno migratorio $-\mathrm{y}$, por tanto, para la adopción de medidas consecuentes- resulta primordial ampliar la perspectiva y profundizar en el conocimiento de dichos países de origen. Estos países se caracterizan por mantener relaciones económicas muy relevantes con numerosos actores internacionales y por un grado considerable, en muchos casos, de dependencia, tanto en relación a la Ayuda Oficial al Desarrollo AOD) que reciben como para el desarrollo de sus industrias extractivas (son las empresas occidentales y de algunas potencias emergentes, como China, las que poseen el capital financiero y la tecnología necesaria), entre las que destacan los hidrocarburos y los minerales. A dichos efectos, el análisis de la trayectoria histórica de estos países -durante su etapa de colonización como en su fase postcolonial- es determinante.

Se trata de países por tanto con una gran riqueza que, sin embargo, han incurrido en la denominada "maldición de los recursos" por obra y gracia de un sistema de expolio protagonizado por las elites africanas en alianza con las multinacionales internacionales, respaldadas frecuentemente por sus respectivos gobiernos. Este sistema de explotación se caracteriza por un expolio de las riquezas sustentado en la utilización de paraísos fiscales (lo que se traduce en ingentes volúmenes de fondos -que superan la AOD- objeto de evasión y elusión fiscal) y una gran corrupción. El resultado son estados rentistas que no han diversificado sus economías y que, por otro lado, han fortalecido sus fuerzas de seguridad, de carácter netamente represivo. A la ausencia de libertades y derechos fundamentales en estos países, se le añaden altos índices de inestabilidad (con el estallido recurrente de conflictos violentos), unos servicios sociales básicos absolutamente deficientes, unos indicadores de desarrollo humano bajo mínimos y amplias capas de la población en condiciones de pobreza extrema.

Este expolio ha generado, en consecuencia, en muchos países, el caldo de cultivo perfecto para que cientos de miles de jóvenes - conectados cada vez más a través de las nuevas tecnologías y las redes sociales a lo que sucede en otras latitudes-decidan emprender la aventura migratoria (en una buena parte de casos, dentro de la propia región subsahariana), aún a riesgo de perder con muchas probabilidades su vida en el intento. El conocimiento de todas estas cuestiones se revela por tanto primordial si realmente se quiere atender al origen y raíz de dicha problemática, de forma multidimensional y con estrategias consecuentes a medio y largo plazo. Hasta el momento, sin embargo, los actores responsables de la situación descrita, continúan con sus dinámicas de explotación de los recursos naturales (marcadas por sus propios por intereses económicos, geopolíticos y de seguridad energética) dejando completamente al margen al conjunto de la población africana, que es en realidad la legítima titular de dichos recursos. 


\section{Primera Mesa Redonda sobre "Aspectos jurídicos de la integración de inmigrantes en el ámbito penal y laboral"}

\section{Moderadora de mesa: Dra. Aurelia Álvarez Rodríguez}

Título Ponencia: "La integración social del extranjero según su talento"

Ponente: Dr. Juan José Fernández Dominguez. Catedrático de Universidad. Derecho del Trabajo y de la Seguridad Social. Universidad de León

Abordar en Derecho el análisis del movimiento internacional del talento supone, como tarea previa, interrogarse sobre sus causas, direcciones e intereses en presencia.

Respecto de los motivos, conviene significar su coincidencia con cuantas actúan en los movimientos migratorios generales, con el catalizador fundamental de las razones económicas-laborales, al cual cabrá añadir los demo-geográficos y los políticosociales.

Convendrá advertir, empero, sobre la diferente incidencia (sector del mercado, mayores facilidades, etc.) que también repercuten en los distintos destinos, pues siendo el Sur-Norte el preponderante en ambas corrientes, cuestiones singulares se abren para los más cualificados, como la batalla entre los países del Norte, la senda Sur-Norte abierta por las multinacionales o la importante influencia del volátil I+D+i.

El debate fundamental quedará situado, no obstante, en explicar si esta es una "fuga de cerebros" que perjudica al receptor (problemas de integración o pérdidas de estímulos educativos), al emigrante (en particular por la infraocupación) y al país de origen (inversiones en educación, falta de personal cualificado, pérdida de inversiones, ...) o, por el contra, un movimiento donde todos salen ganado, incluso quienes deben desprenderse de los mejores y más valiosos (incentivos al estudio, recuperación de "cerebros", aprovechamiento de su propiedad intelectual, remesas o actuación de las diásporas). Sobre el balance final se ha de asentar la reflexión jurídica, con un doble y grave hándicap de partida: de un lado, existe un derecho universal a emigrar, pero no el correlativo a inmigrar; de otro, en esa "guerra" por el talento todo vale, abandonando el problema a leyes nacionales tan cicateras con el resto, como favorables cuando vislumbran un beneficio más que potencial.

Para un estudio más detallado, vid. FERNÁNDEZ DOMINGUEZ, J.J.: "El movimiento internacional de trabajadores altamente cualificados: claves previas para su análisis en los ordenamientos jurídicos europeo y español", FERNÁNDEZ FERNÁNDEZ, R. (Dir.), ÁLVAREZ CUESTA, H. (Coord.), Empleo juvenil: Un reto para Europa (Youth employment: A challenge for Europe), Civitas Aranzadi, 2016.

Título Ponencia: "Integración laboral de las mujeres inmigrantes"

Ponente: Dr. Roberto Fernández Fernández. Profesor Titular de Universidad. Derecho del Trabajo y de la Seguridad Social. Universidad de León 
Un repaso por las diferentes actuaciones de los poderes públicos en materia de fomento del empleo y la ocupación de las mujeres inmigrantes lleva a colegir que la perspectiva de género no ha sido incorporada a las políticas de empleo destinadas a los inmigrantes por parte de las Administraciones españolas. En este sentido, las trabajadoras extranjeras únicamente pueden acceder a las medidas de inclusión en el mercado laboral español por su condición de mujer o por su estatus de inmigrante, si bien esta última condición tampoco ha sido objeto de reconocimiento expreso por parte del legislador español a la hora de desarrollar y ejecutar su política de empleo, más allá de su reconocimiento como personas con dificultades de integración en el artículo 19.octies. 1 de la Ley 56/2003.

A la circunstancia normativa anterior, cabe hacer referencia a cuanto ha sido denominado un triple factor de discriminación que dificulta la inserción laboral de las mujeres inmigrantes en España: en primer término, su género, habida cuenta el sistema español de relaciones laborales dista mucho de alcanzar la tan ansiada igualdad de trato entre hombres y mujeres; en segundo, el lugar de nacimiento, pues el tratamiento hacia el extranjero está cargado de estereotipos y tópicos comunes que impiden una adecuada incorporación al mercado laboral; en fin, la incorporación de este colectivo de trabajadoras en actividades y sectores de empleo oculto o sumergido $\mathrm{y}$, en ocasiones, ilícito $\mathrm{y}$, cuando encuentran un trabajo legal, lo hacen en sectores netamente precarizados, en los cuales las condiciones laborales no son las más óptimas, como puede ser el servicio doméstico o el cuidado de dependientes.

De ahí, que no falten voces que abogan por solicitar de los poderes públicos una atención específica para este colectivo, estableciendo medidas tendentes a fomentar su contratación e incorporación al sistema español de relaciones laborales, luchando contra las desigualdades que las mujeres extranjeras sufren en el acceso a un empleo.

Título Ponencia: "La integración laboral de las víctimas de trata de seres humanos y explotación sexual"

Ponente: Dra. Henar Álvarez Cuesta. Profesora Titular de Universidad. Derecho del Trabajo y de la Seguridad Social. Universidad de León

La trata de seres humanos es un fenómeno de preocupantes dimensiones que constituye una de las más escandalosas y sangrantes formas de reducción del ser humano a simple mercancía, y representa una de las violaciones más graves de los derechos humanos. La trata de seres humanos con fines de explotación sexual, especialmente de mujeres y de niñas, sus principales víctimas, constituye una de las vertientes más crueles de este ilícito comercio. Es, en realidad, una manifestación más de la situación de desigualdad en la que se encuentran las mujeres en muchos lugares del mundo y constituye una clara expresión de la violencia de género.

La integración social camina por la senda del empleo (o autoempleo), y tal sucede también con las víctimas de trata de seres humanos o explotación sexual. Sin embargo, y a salvo la autorización temporal destinada sólo a inmigrantes "irregulares", no 
existía medida específica alguna destinada a favorecer el acceso de estas mujeres a un trabajo digno.

A nadie escapa que constituyen un colectivo en claro riesgo de exclusión social, sin embargo, ni la Ley 5/2011, que regula la economía social; ni la más específica Ley 44/2007, para la regulación del régimen de las empresas de inserción, incluyen de manera directa a las víctimas de trata de seres humanos o de explotación sexual. Bien es cierto que, de forma indirecta, sí lo hace esta última, al considerar en riesgo de exclusión a cualquier persona que esté percibiendo una renta mínima de inserción (o no pudiera acceder a dichas prestaciones por faltarle el período exigido de residencia o empadronamiento) o provenga de centros de alojamiento alternativo o de servicios de prevención e inserción social.

Al examinar los requisitos impuestos por las distintas Comunidades Autónomas para resultar beneficiario de dichas rentas (o la propia de renta estatal), de nuevo, salvo error u omisión, ninguna prevé excepción alguna que favorezca su otorgamiento a este colectivo (similares, por ejemplo, a las previstas para las víctimas de violencia de género). Por tanto, las víctimas de trata de seres humanos o explotación sexual son sometidas a los férreos requisitos comunes; únicamente, la Ley 10/2013, de 27 de noviembre, de Inclusión social de Galicia, regula la tramitación abreviada para su concesión.

De trasladar esta ausencia de consideración legal específica a las distintas políticas activas de empleo previstas en las normas españolas, y pese a que la Ley 56/2003 señala entre sus objetivos asegurar políticas adecuadas de integración laboral dirigidas a aquellos colectivos que presenten mayores dificultades de inserción laboral, especialmente -entre otros-, mujeres, las distintas medidas fruto de las sucesivas reformas legales en este ámbito han olvidado también prestar atención (y por ello, diseñar ayudas ad hoc) para este colectivo. Ni el contrato indefinido de apoyo a emprendedores; ni las bonificaciones previstas en la Ley 43/2006, las menciona expresamente (como sí hace con las víctimas de violencia de género) y sólo accederán a estos instrumentos si han sido considerados previamente trabajadores en situación de exclusión social (conforme a las reglas comunes anteriores).

Por su parte, las Leyes 11 y 14/2013, ambas de apoyo al emprendimiento, mantienen el silencio sobre las víctimas de trata de seres humanos o explotación sexual, centrando su atención en los jóvenes, personas con discapacidad o parados de larga duración.

Pero esta falta de sensibilidad del legislador, traducida en carencia de instrumentos específicos que favorezcan la inserción laboral de las víctimas, no siempre fue tal. El pretérito contrato para el fomento de la contratación indefinida sí contemplaba, como colectivo incluido, a las "mujeres desempleadas víctimas de violencia de género y de trata de seres humanos" (disposición adicional primera de la Ley 12/2001, de 9 de julio), introducido este colectivo por la Ley 35/2010, de 27 de septiembre y derogada esta disposición por el RD-Ley 3/2012, de 10 de febrero. Su recorrido fue, en definitiva, muy corto, hasta el punto de no poder hacer una valoración sobre su alcance y efectividad. 
La Ley 26/2015, de 28 de julio, de modificación del sistema de protección a la infancia y a la adolescencia, en su disposición final $8^{\mathrm{a}}$ introduce un nuevo apartado 4 ter en el art. 2 de la Ley 43/2006, de 29 de diciembre, para la mejora del crecimiento y del empleo: "los empleadores que contraten indefinidamente a víctimas de trata de seres humanos, identificadas de acuerdo con lo dispuesto en el artículo 59 bis de la Ley Orgánica 4/2000, de 11 de enero, sobre derechos y libertades de los extranjeros en España y su integración social, y que, en su caso, hayan obtenido la autorización de residencia y trabajo por circunstancias excepcionales, sin que sea necesaria la condición de estar en desempleo, tendrán derecho, desde la fecha de celebración del contrato, a una bonificación mensual de la cuota empresarial a la Seguridad Social o, en su caso, por su equivalente diario, por trabajador contratado, de 125 euros/mes (1.500 euros/año) durante 2 años.

Título Ponencia: "El Derecho penal al servicio de la integración de los inmigrantes en España: el delito de matrimonio forzado"

Ponente: Dra. María Anunciación Trapero Barreales. Profesora Titular, acreditada Catedrática, de Derecho Penal. Universidad de León

En la comunicación se aborda la utilización del nuevo delito de matrimonio forzado en la lucha contra determinadas prácticas atentatorias contra derechos fundamentales que suelen afectar particularmente a mujeres y niñas procedentes de determinados países.

Como cuestión previa se contextualiza esta práctica, haciendo hincapié en la necesaria delimitación conceptual, para evitar que, bajo el pretexto de la lucha contra los matrimonios forzados, se utilice el Derecho penal para la prevención de determinadas prácticas producto de tradiciones y culturas diferentes, convirtiéndose así el delito de matrimonio forzado en un mero delito cultural. Porque en una sociedad plural de un Estado social y democrático de Derecho se ha tener especial cuidado para el máximo respeto de culturas y tradiciones de las personas que, por distintas razones, llegan a nuestro país, huyendo de cualquier política que suponga su asimilación. El respeto a tradiciones y culturas ha de estar garantizado, con el límite de que no supongan un atentado contra un derecho fundamental (como puede suceder con la práctica del matrimonio forzado).

Tras la delimitación conceptual, se ofrece información sobre la incidencia de esta clase de matrimonios en nuestro país, una práctica escasamente conocida en España, salvo algún dato estadístico recogido en Cataluña, explicado este hecho porque la legislación autonómica de esta Comunidad Autónoma sobre la violencia de género o violencia contra la mujer de manera específica alude a este tipo de prácticas.

En esta fase previa, dirigida a delimitar claramente el problema de los matrimonios forzados, se insiste en dos aspectos importantes: existe íntima relación o conexión entre matrimonio forzado y violencia de género o contra la mujer, por un lado, y entre matrimonio forzado e inmigración, por otro lado. Pero esta conexión o relación no significa identificación, ni con uno ni con otro fenómeno. 
A continuación, se aborda de qué manera se ha pretendido utilizar el Derecho Penal en la prevención de los matrimonios forzados, porque en la reforma operada por la LO 1/2015, de 30 de marzo, se ha introducido en este texto legal un nuevo delito con este nomen iuris. Se hace especial hincapié en los aspectos problemáticos que plantea esta nueva figura delictiva, a la vista de los elementos que configuran esta nueva modalidad delictiva, pensada para dar un tratamiento agravado a este ataque contra la libertad, pero que, en comparación con otras figuras delictivas ya existentes, puede resultar el efecto contrario al perseguido: un tratamiento benévolo.

Finalmente se destacan los cambios que en la reforma de 2015 también se han realizado en otra figura delictiva, el delito de trata de personas, en concreto, con la introducción expresa de una nueva finalidad, la celebración de matrimonios forzados. Un cambio legislativo que va a provocar enormes problemas concúrsales entre este delito, dirigido a la protección de la dignidad, y el delito de matrimonios forzados, pensado para la protección del derecho a contraer matrimonio libremente (y en igualdad, en términos planteados por el Consejo General del Poder Judicial).

\section{Título Ponencia: "La mutilación genital femenina desde el punto de vista del Derecho penal"}

Ponente: Dra. Isabel Durán Seco. Profesora Contratada Doctora (acred. Titular) de Derecho Penal. Universidad de León

El fenómeno migratorio supuso un mayor pluralismo cultural, religioso e ideológico, lo que hizo que la mutilación genital femenina llegase a España. El Estado no puede admitir, bajo el alegato a la libertad de conciencia o amparo de la tradición y de la costumbre, todas las actuaciones que según criterios individuales sean conformes a los dictados de la conciencia, pues esto supondría olvidar la afectación de bienes jurídicos de fundamental importancia como, por ejemplo, pueden ser la vida o la integridad física.

Las razones que se alegan para practicar en ciertos grupos humanos la mutilación son múltiples. Las consecuencias que con esta práctica se producen son tanto lesiones físicas como psíquicas.

La relevancia jurídico-penal de esta conducta es indiscutible, pues se considera que la práctica de mutilaciones genitales (normalmente femeninas) supone un atentado a la integridad física y mental, concretamente un delito de lesiones recogido en los artículos $147 \mathrm{ss}$. del CP. Entre las distintas modalidades de lesiones que se distinguen en nuestro $\mathrm{CP}$ encontramos la que diferencia, a la hora de imponer la pena, entre que se haya causado la pérdida o inutilidad de un miembro u órgano principal o no principal.

La cuestión en esta materia estribaría en determinar si el clítoris es un miembro u órgano principal, y de ese modo castigar la conducta con mayor pena, en concreto con la pena de 6 a 12 años o, si, por el contrario, se considera no principal y castigarlo con la pena de 3 a 6 años de prisión. 
Fue la LO 11/2003 la que decidió darle el carácter de principal y modificó art. 149 CP. La reforma consistió en la introducción de forma expresa de la mutilación genital, es decir, en que la mutilación genital pasase a constituir un delito autónomo, al igual que ocurre en muchos países de la UE. Asimismo, se previó la posibilidad, si la víctima fuese menor o persona con discapacidad necesitada de especial protección, de imponer la pena de inhabilitación especial para el ejercicio de la patria potestad, tutela, curatela, guarda o acogimiento.

Más importante era el problema del enjuiciamiento por parte de nuestros tribunales de estos hechos cuando se habían realizado fuera de nuestro territorio, pues atendiendo al principio de territorialidad ello no era posible. De ahí que a través de la LO 3/2005 se modificase el art. 23 LOPJ permitiendo que se pudiese aplicar la ley española a supuestos de mutilación genital, aunque no hubieran ocurrido en España (principio de universalidad o de justicia universal).

\section{En la segunda sesión, el día 27 de octubre, en jornada de mañana y de tarde se impartieron varias ponencias y se realizó una mesa redonda.}

Título Ponencia: "La integración de inmigrantes a través del acceso a la nacionalidad española: especial análisis de la Ley 12/2015"

Ponente: Dra. Marina Vargas Gómez-Urrutia. Profesora titular de Derecho internacional privado. UNED

La profesora Vargas Gómez-Urrutia da cuenta en su ponencia de las novedades establecidas en la Ley 12/2015, de 24 de junio que ha venido a establecer un "nuevo procedimiento" para la adquisición de la nacionalidad española por carta de naturaleza para los sefardíes originarios de España.

Tras una breve exposición sobre la tramitación parlamentaria de la Ley 12/2015 en que se puso de relieve las vicisitudes del proyecto de Ley tanto en el Congreso como en el Senado y, en particular, se destacó la falta de coherencia entre el texto finalmente aprobado y la Exposición de Motivos, la ponencia se centró en el análisis del nuevo procedimiento que establece la Ley.

De modo sintético, se destacó la complejidad del procedimiento (electrónico) que obedece, en opinión de la ponente, a la multiplicidad de autoridades administrativas intervinientes y a la difícil, y en ocasiones innecesaria, prueba de la condición de sefardí originario de España y el reconocimiento de su vinculación con España.

Por lo que respecta a las autoridades intervinientes, la ponente destacó la multiplicidad de autoridades, lo que puede restar eficacia al procedimiento, y se centró en la comparecencia ante Notario (una vez presentada la solicitud en la plataforma habilitada al efecto por el Ministerio de Justicia) siendo esta autoridad la que habrá de verificar la certeza de los hechos en que se funda la solicitud de la nacionalidad. 
Otra de las novedades de la Ley, quizá la más relevante (también se exige en el nuevo procedimiento de adquisición de la nacionalidad española por residencia regulado en el RD 1004/2015) se refiere a la prueba de integración articulada en torno al obligatorio test del Instituto Cervantes.

La norma establece que si el interesado es mayor de dieciocho años $-\mathrm{y}$ no tiene la capacidad modificada judicialmente--, se exigirá la superación de dos pruebas, una de conocimiento básico de la lengua española (con obtención de un diploma de español como lengua extranjera DELE de nivel A2 o superior) y otra sobre la Constitución y la realidad social y cultural españolas. Esta cuestión dio lugar a un interesante debate entre los asistentes.

Título Ponencia: "La integración de inmigrantes a través del acceso a la nacionalidad española: especial análisis del Proyecto de Reglamento de naturalización por residencia"

Ponente: Dra. Aurelia Álvarez Rodríguez. Profesora titular, acreditada Catedrática, de Derecho internacional privado. Universidad de León

La Disposición final $7^{\mathrm{a}}$ de la Ley 19/2015, de 13 de julio, de medidas de reforma administrativa en el ámbito de la Administración de Justicia y del Registro Civil imponía una reforma sobre la forma de acreditar el requisitos exigido para obtener la nacionalidad española por residencia. El 15 de octubre entraba en vigor un nuevo procedimiento de naturalización por residencia. Ahora bien, su adopción se demoro tres semanas, al no ser aprobado hasta la reunión celebrada por el Consejo de Ministros de 6 de noviembre de 2015, en el que se dio el visto bueno al RD 1004/2015. De sus disposiciones se deducen varios cambios muy importantes en la tramitación de las solicitudes de naturalización por residencia: se regula un procedimiento de carácter netamente administrativo, basado en la tramitación electrónica en todas sus fases con el fin de acortar sensiblemente los plazos de resolución. Así pues, tramitación del procedimiento tendrá carácter electrónico y su instrucción corresponderá a la DGRN; el requisito sustantivo relativo a los plazos de residencia exigidos si bien continua regulado en el Código Civil, su acreditación así como la exigencia de buena conducta y la suficiente integración en la sociedad española deberán ser probadas mediante los documentos y demás pruebas previstas en la ley y reglamentariamente. La acreditación del suficiente grado de integración en la sociedad española requerirá la superación de dos pruebas que serán diseñadas y administradas por el Instituto Cervantes. Además, este procedimiento estará sujeto al pago de una tasa de 100 euros a abonar por la iniciación de la petición para obtener la nacionalidad española por residencia. Dicha tasa no incluye los precios de las pruebas de examen DELE y de conocimientos constitucionales y socioculturales de España (CCSE).

\section{Título ponencia: "Requisitos lingüísticos y conocimientos constitucionales y socioculturales para la obtención de la nacionalidad española" \\ Ponente: Dra. Milka Villayandre Llamazares. Profesora de la Facultad de Filosofía y Letras. Universidad de León}


La entrada en vigor en octubre de 2015 de las Leyes 12/2015 y 19/2015 ha significado, además de otros requisitos, la necesidad de superar dos pruebas para aquellos que desean acceder a la nacionalidad española: una prueba de conocimientos lingüísticos y otra de conocimientos constitucionales y socioculturales, ambas diseñadas y administradas por el Instituto Cervantes a instancias del Ministerio de Justicia.

Los destinatarios son aquellas personas mayores de edad que quieran obtener la nacionalidad española, incluidos los sefardíes originarios de España. Quedan exentos de la realización de las dos pruebas los menores de edad y las personas tuteladas; y de la prueba de conocimientos lingüísticos, los nacionales de países o territorios en los que el español es idioma oficial.

En concreto, la prueba lingüística que se exige es el Diploma de Español como Lengua Extranjera (DELE) de nivel A2 o superior, título oficial que otorga el Ministerio de Educación, Cultura y Deporte en España, con reconocimiento internacional. Este examen es obligatorio para todos los candidatos no hispanohablantes.

No se trata de una prueba nueva, sino que forma parte de las certificaciones en los seis niveles (A1, A2, B1, B2, C1 y C2) que reconoce el Marco Común Europeo de Referencia para las Lenguas en el contexto europeo. La superación del DELE A2 "acredita que el candidato es capaz de comprender frases y expresiones cotidianas de uso frecuente relacionadas con áreas de experiencia que le son especialmente relevantes (información básica sobre sí mismo y su familia, compras, lugares de interés, ocupaciones, etc.)".

Este examen consta de dos partes: una centrada en las destrezas de lectoescritura (comprensión de lectura -60 minutos-, y expresión e interacción escritas -50 minutos-) y la otra, en las destrezas orales (comprensión auditiva -35 minutos- y expresión e interacción orales -15 minutos-). El candidato debe superar las dos partes con un mínimo de 30 puntos en cada una (el máximo posible en el examen son 100 puntos) para poder obtener calificación de apto.

Existen cinco convocatorias ordinarias al año, fijadas por el Instituto Cervantes, en abril, mayo, julio, octubre y noviembre. La inscripción se abre el 15 de febrero. Para el 2016, las fechas son: 15 de abril (inscripción hasta el 16 de marzo), 21 de mayo (inscripción hasta el 13 de abril), 15 de julio (inscripción hasta el 8 de junio), 21 de octubre (inscripción hasta el 14 de septiembre) y 26 de noviembre (inscripción hasta el 19 de octubre).

No obstante, cada centro examinador decide, en función de sus recursos y planificación, en qué convocatorias participar, es decir, no todos los centros administran todas las convocatorias. En el caso de la Universidad de León se ha optado por examinar del DELE A2 en todas ellas. Además, en 2016, el Instituto Cervantes se ha visto obligado a realizar una convocatoria extraordinaria el pasado 19 de febrero, ante la gran demanda de candidatos a los que les caducaba la validez de otros documentos. 
El coste del examen DELE A2 es de 124 euros, tarifa fijada y aprobada anualmente por el Instituto Cervantes. La inscripción y pago de las tasas de examen debe realizarse directamente a través de la página web del Cervantes (https://ccse.cervantes.es/), y es válida únicamente para un nivel y convocatoria, por lo que si el candidato no supera el examen debe volver a inscribirse y abonar las tasas correspondientes. Los resultados son comunicados por el Instituto Cervantes al candidato en un plazo aproximado de dos meses (a través de la web, con el código de inscripción). Cuando el candidato obtiene el apto, el diploma acreditativo es enviado al centro examinador por el Instituto Cervantes seis meses después de la fecha de examen. El centro se lo envía después al candidato por correo certificado. El diploma tiene una validez indefinida. La otra prueba exigida, en este caso obligatoria para todos los candidatos con independencia de su lengua materna, se refiere a conocimientos constitucionales y socioculturales de España (CCSE). Consta de 5 tareas y 25 preguntas de respuesta cerrada (tipo opción múltiple o verdadero/falso). El 60\% de los contenidos abarca conocimientos sobre gobierno, legislación y participación ciudadana en España; el $40 \%$ restante está relacionado con cultura, historia y sociedad españolas. La superación de la prueba (apto) exige un mínimo de 15 respuestas correctas. La realización de la misma dura 45 minutos, desde las 18.00 hasta las 18.45 , aunque los candidatos son convocados a las 17.30 para efectuar la comprobación de identidad y la colocación en el aula de examen. Para la preparación del examen, disponen de un manual, actualizado cada año, con una batería de 300 preguntas de las que se extraen las del examen.

Este está elaborado siguiendo la norma culta del español contemporáneo peninsular. Por lo tanto, implica un cierto nivel de exigencia lingüística y el dominio de la comprensión lectora, además de los conocimientos específicos que evalúa. El Instituto Cervantes señala que se realiza una adaptación del nivel lingüístico en la formulación de las preguntas con el objeto de facilitar su comprensión, lo que conlleva una merma de la precisión jurídica en algún caso.

Esta prueba (CCSE) se realiza el último jueves de cada mes, excepto en agosto y diciembre. Por lo tanto, los candidatos disponen de 10 convocatorias al año aunque, como en el caso del DELE, cada centro examinador decide en qué convocatorias participa (tiene obligación de hacerlo en el 75\% de las mismas). La Universidad de León, como centro examinador acreditado, ha decidido participar en todas las convocatorias.

La inscripción para la prueba se efectúa en la web específica del Instituto Cervantes (https://ccse.cervantes.es/), previo registro. Las tasas de examen tienen un coste de 85 euros y dan derecho a presentarse a dos convocatorias, en el mismo centro de examen, dentro de 18 meses, si suspende o no se presenta a la primera convocatoria.

Desde la citada web, el candidato tiene acceso a los detalles de su inscripción, a la revisión de la calificación y a la descarga del certificado (cuando supera el examen). La vigencia del certificado es de 4 años desde la fecha de la convocatoria en que se obtiene. 


\section{En la jornada de tarde del día 27 se prosiguió con las ponencias y la realización de una mesa redonda.}

Título Ponencia: "Luces y sombras de la inmigración en la UE desde la perspectiva económica"

Ponente: Dra. Nuria González Rabanal. Profesora. Facultad de CC. Económicas y

Empresariales de la ULE. Decana del llustre Colegio de Economistas de León.

Directora del proyecto "The europeans citizens Racing the integration challenges"

Si el tema de las migraciones despierta el interés y la controversia a nivel jurídico y social, qué duda cabe que también lo hace a nivel económico.

Para la Unión Europea el reto de las migraciones va más allá de la frontera del debate moderado que siempre ha dominado sus instituciones políticas en tiempos de bonanza, dado que en el momento en el que nos encontramos - una Europa dividida por la crisis económica donde emergen los radicalismos ideológicos- ya no sólo hay que pensar hacia fuera sino también hacia dentro.

El problema migratorio adquiere dimensión poliédrica cuando se intentan al mismo tiempo garantizar los derechos de quienes huyen del conflicto armado o las guerras éticas - fuertemente vinculadas con la mala interpretación del islamismo- en busca de un bienestar que parece ofrecerles la UE, con la protección del bienestar y seguridad de quienes siempre prometimos ese refugio y la garantía de solidaridad siempre hablada pero nunca tan necesaria como hasta ahora.

Durante años se ha pensado en los inmigrantes como una solución más que un problema en Europa. Con una población longeva y creciente en número y unas tasas de natalidad bajas, la llegada de mano de obra que contribuya al sostenimiento del Estado del Bienestar es siempre bienvenida. Sin embargo, ese espejismo se desvaneció con la crisis económica, crisis que arrojó al desempleo a millones de trabajadores europeos del mal llamado pero real "sur" de Europa, puerta de entrada además de los flujos de refugiados. El masivo desempleo sometió a estrés las políticas públicas de los Estados miembros que tenían además de unas menguadas cuentas, un déficit público que les impedía gastar más e ingresar más. El resultado es que allí donde llegan más refugiados es donde más estranguladas están las ayudas públicas y donde nacionales y recién llegados compiten por la garantía de los derechos básicos.

Otra de las caras del problema lo representa el propio problema de integración de los inmigrantes y su nivel de cualificación. Si algo está claro incluso para los propios desempleados europeos es que el mercado de trabajo es muy dinámico y que la formación es clave para resolver el desempleo. Si le resulta difícil a la UE adecuar su propia mano de obra a los cambios del mercado de trabajo, cuanto más no le resultará formar mano de obra que además ha de enfrentarse a una barrera idiomática y cultural.

Por último debemos pensar en el sostenimiento del Estado del Bienestar. Europa, con sus diferencias internas ha sido considerada un ejemplo -susceptible de mejora- en materia de educación, sanidad, y pensiones. En una coyuntura en la que la austeridad 
domina como regla de medida para la salida de la crisis, donde no es posible aumentar el gasto público, en el que los que los sistemas de pensiones están forzando no sólo a un aumento de la edad de jubilación, sino a una quiebra a largo plazo del mismo... ¿Dónde encajan la necesaria solidaridad que ha pregonado la UE?

\section{Mesa Redonda: "Aspectos de la integración de extranjeros en España y América Latina: visión multidisciplinar"}

\section{Moderador de mesa: D. David Carrizo Aguado}

Título Ponencia: "Respuestas jurídicas a la integración de las minorías religiosas en España"

Ponente: Dr. Salvador Tarodo Soria. Profesor Titular de Derecho Eclesiástico del Estado. Universidad de León

Las políticas de integración deben perseguir el objetivo de hacer compatible la igualdad de derechos y deberes con una diversidad enriquecedora. Consecuencias de esta perspectiva serían políticas de visibilidad de la diferencia y la presencia en el espacio público de las diferentes opciones de vida. Las opciones religiosas no deben ser confinadas al ámbito de lo privado, lo que no significa que puedan confundirse con los poderes públicos ni que puedan utilizar directa o indirectamente los instrumentos coactivos del Estado para finalidades propias del grupo religioso.

En nuestro ordenamiento jurídico puede constatarse una falta de sensibilidad jurídica hacia el reconocimiento de las minorías étnicas, culturales y religiosas. La prácticamente inexistente presencia de minorías étnicas en el origen de nuestro Estado, su configuración en torno a un monismo ideológico y religioso que ha perdurado durante buena parte de nuestra Historia o la relativamente reciente aparición del pluralismo cultural, moral y religioso, pueden ser algunos de los factores histórico-sociológicos que expliquen estas carencias.

La normativa específica sobre minorías es muy escasa, genérica y de efectos muy limitados. La Constitución únicamente contiene referencias a las nacionalidades (art. $2 \mathrm{CE}$ ) y a las distintas modalidades lingüísticas (art. 3.3 CE) y los tratados internacionales ratificados por España en materia de minorías han restringido su aplicación a las minorías nacionales, lingüísticas y étnicas que ya se encuentren arraigadas en nuestro país, quedando fuera las minorías no arraigadas o formadas por no nacionales, que en una España, cuyo pluralismo proviene en buena medida de la reciente inmigración, serían la inmensa mayoría. Los instrumentos jurídicos internacionales se muestran, de esta forma, claramente insuficientes para atender la especificidad de la situación española.

Las minorías étnicas, culturales y religiosas, se ven obligadas, de esta forma, a buscar el reconocimiento de sus singularidades a través de otros dos sectores del ordenamiento jurídico: la normativa de extranjería y la normativa que regula el ejercicio colectivo de la libertad religiosa. 
La reciente normativa de extranjería aun cuando contempla la integración de los extranjeros como un objetivo prioritario de las políticas públicas, ha resultado decepcionante en su desarrollo. Además, la asociación del discurso de la diversidad a la extranjería provoca una estigmatización de las minorías y un rechazo de la sociedad de acogida, impidiendo un tratamiento diferenciado de las cuestiones jurídicas sobre minorías y dificultando que las respuestas jurídicas atiendan a su verdadera problemática y fundamentación, que es distinta en el caso del extranjero que en el de las reivindicaciones minoritarias.

El otro eje por el que los grupos minoritarios pueden obtener reconocimiento jurídico de algunas de sus demandas es agrupándose en torno al elemento diferencial de carácter religioso. La asociación del discurso de la diversidad al ejercicio colectivo de la libertad religiosa se ve afectada por la existencia de un régimen jurídico desigual e impulsa a las minorías étnicas y culturales a nuclearse en torno al fenómeno religioso, planteando serios problemas de compatibilidad con la igualdad, la laicidad y la seguridad del Estado.

La regulación del ejercicio colectivo de la libertad religiosa mediante un régimen jurídico diverso y escalonado tiene efectos muy perniciosos respecto a las minorías étnicas y culturales, pues si quieren verse beneficiadas de un régimen jurídico favorable se ven abocadas a constituirse e identificarse en torno al factor religioso. Algo que parece contrario a varios principios: (1) en primer lugar, al principio de igualdad, ¿qué argumento permite sostener que la identidad religiosa es más relevante y merece más protección jurídica que la identidad étnica o cultural?; (2) en segundo lugar, al principio de laicidad, pues hay una valoración positiva del fenómeno religioso, respecto a otras creencias no religiosas; e incluso (3) a la propia seguridad del Estado, pues estamos dando a las minorías recién llegadas un mensaje contradictorio, por un lado, les decimos que llegan a un país laico en el que tal vez tengan que renunciar a determinadas convicciones que impliquen una confusión entre poder político y poder religioso $\mathrm{y}$, por otro lado, que obtienen un mayor reconocimiento jurídico si se organizan en torno al elemento religioso.

Para un estudio más detallado, vid: TARODO SORIA, S., "Minorías, identidades abiertas y libertad de conciencia", en ABAD CASTELOS, M/ BARRANCO AVILÉS, M.C. / LLAMAZARES CALZADILLA, Ma . C. (Eds.), Derecho y Minorías, Dykinson, 2015, pp. 79-116.

Título Ponencia: "Modelos de integración socio-cultural en un mundo globalizado"

Ponente: Dña. Tamara Álvarez Robles. PDI en formación. Universidad de León

El objeto de mi participación en el III Seminario sobre relaciones jurídicas internacionales, celebrado en la Facultad de Derecho de la Universidad de León, es darles a conocer de forma esquemática e introductoria algunos de los modelos existentes sobre integración socio-cultural, tomando para ello la visión estatal y no tanto la del migrante que accede al Estado en cuestión. 
De este modo, pudimos observar como el Estado receptor de la inmigración se sitúa, en un primer momento, en una posición de aceptación, gestión si se prefiere, o bien de rechazo, cerrando sus fronteras e impidiendo cualquier entrada de inmigración.

Tras ese primer posicionamiento, y en el caso de que optase por la integración, en un segundo momento, hablaríamos de una triple categorización, en función del grado de aceptación de diversidad cultural, de modelos de gestión, a saber: la aculturación, la integración socio-cultural, en sus diferentes formas, e incluso podría producirse un modelo intercultural o multicultural.

La aculturación, tendría lugar cuando la inmigración es vista como un problema, pues supondría la pérdida de la identidad cultural nacional, hablamos de un adoctrinamiento que se produce generalmente en aquellos Estados en los cuales hay un fuerte arraigo del concepto tradicional de Estado-Nación o un fuerte componente religioso unido al mismo.

La verdadera aceptación del inmigrante pasa por los distintos grados de integración cultural. En este caso, los inmigrantes son equiparados a los nacionales, por lo que no es tanto un problema como un factor condicionante que ha de ser tratado con el mayor respeto a los derechos de los inmigrantes y con las respectivas garantías, y sólo en caso de confrontación de culturas habrán de ser ponderadas prevaleciendo aquella que respeta los derechos fundamentales $\mathrm{e}$ indisponibles de las personas $\mathrm{e}$ internacionalmente reconocidos (límite). A su vez han de acaecer dos circunstancias: que el Estado permita al inmigrante la elección de mantener o no su cultura a la par que brinda mecanismos, políticas públicas y normas, para que esa persona pueda elegir libremente, sea reconocido y participe activamente en el propio Estado, y, por otro lado, que las culturas de origen y destino se encuentren abiertas o permeables favoreciendo la interculturalidad.

Una pauta de actuación que va más allá de la propia integración cultural supondría hablar de la gestión de la multiculturalidad, una vez que entendemos esa aceptación del inmigrante, implica el rechazo a los prejuicios, el respeto a la diversidad, el reconocimiento mutuo de las diferentes culturas y la garantía de derechos y valores universales de dignidad, libertad, igualdad, solidaridad, ciudadanía y justicia. Hablamos de interculturalidad, entendiendo por lo tanto no sólo la presencia de distintas culturas sino la interacción y la convivencia armónica de éstas.

Respecto al plano estatal interno, y una vez definidas las tres categorías, cabría preguntarse hasta dónde puede un Estado intervenir culturalmente y hasta donde no, dado que uno de los resultados de la globalización es la cohabitación de varias culturas, etnias o grupos dentro de un mismo Estado. Ante esta situación pluricultural podríamos decir que existe una predilección por aquellos modelos de gestión de la inmigración que defienden la tesis de que el Estado no debe mostrar posturas bien de rechazo de la inmigración o bien de aculturación, sino que ha de optar preferiblemente por aquellas de asimilación e integración.

De este modo el Estado, en sus diferentes niveles, estará legitimado para intervenir participando mediante políticas públicas del fomento de la interculturalidad, 
corrigiendo aquellos efectos perversos que pudiesen originarse como el surgimiento de guetos, la xenofobia, la marginación, la falta de representación... a la par que asegura los derechos fundamentales y humanos a los inmigrantes; sin embargo no sucedería lo mismo ante posiciones que pasen por la aculturación, por la búsqueda de una homogeneidad cultural y el exterminio de toda diferencia socio-cultural.

Todos los intervinientes por orden de aparición:

Título de la Ponencia: "La integración en Colombia: lo que la historia nos aporta" el fenómeno migratorio y la trata de personas"

Ponente: D. Juan Pablo Uribe Barrera. Contratado Predoctoral. Universidad de León

La ponencia parte de una simple premisa: los ordenamientos jurídicos actuales (pensados, de manera general, para sociedades monoculturales o con pequeñas manifestaciones de algún pluralismo cultural) sufren complejas tensiones con motivo de los constantes flujos económicos derivados del modelo económico global y de la inestabilidad política de ciertas regiones. Ante el reto que surge de este panorama, se propone que puede resultar de algún interés, como caso de estudio, observar, no sin problematizar ni analizar críticamente, el abanico de soluciones jurídicas que se han generado en Colombia para dar un tratamiento a situaciones de corte similar. Más concretamente, se propone dirigir la mirada sobre las alternativas jurídico penales que se han elaborado en aquel país para aceptar el reto de proteger los bienes jurídicos de los ciudadanos sin afectar con ello la riqueza étnica y cultural de la nación, que allí se representa, entre otras muchas formas, con la existencia de cientos de grupos indígenas que a pesar de siglos de lucha por su exterminación, han logrado permanecer anclados a ciertos territorios en las periferias del país.

En una primera fase de la exposición, se trata de enseñar entonces que la situación ha adquirido la máxima relevancia constitucional, pues precisamente la Constitución Política de 1991 asienta los pilares del tratamiento jurídico que se propone para enfrentar los conflictos multiculturales que se puedan presentar en el territorio colombiano. El expreso reconocimiento y protección de la diversidad étnica y cultural de la Nación colombiana, así como la obligación que se adjudica al Estado y a los ciudadanos para protegerlas (artículos 7 y 8); la consagración de un derecho a la igualdad que a su vez obliga al Estado a, por una parte, promover condiciones para que la igualdad sea efectiva y real adoptando medidas en favor de grupos discriminados o marginados, con especial atención a aquellos que se encuentren en circunstancias de debilidad manifiesta, y, por otra, a sancionar aquellos abusos o maltratos que contra éstos se cometan (artículo 13); el reconocimiento de la igualdad y dignidad de todas las culturas que conviven el país (artículo 70); y, por fin, la creación de una figura denominada fuero especial indígena, a través de la cual se confiere a las autoridades de los pueblos indígenas la posibilidad de ejercer funciones jurisdiccionales dentro de su ámbito territorial y de conformidad con sus propias normas y procedimientos, siempre que éstos no sean contrarios a la Constitución y leyes de la República. 
En la segunda fase de la ponencia, luego de enseñar algunos de los desarrollos normativos que se han producido bajo la égida de los comentados parámetros constitucionales, se abordan las diversas problemáticas que han tenido estas estructuras normativas al ser puestas en práctica por los operadores jurídicos. Se enseña que la práctica judicial, a juicio del ponente, se ha mostrado, por una u otra razón, corta en explotar todas las posibilidades y alcances que la Constitución Política colombiana ofrecía. Sin ser el espacio para desarrollar cada uno de los problemas que en la ponencia se abordaron con detalle, si cabe aquí adelantar que el hilo conductor en la resolución jurídica de conflictos permite observar diáfanamente una valoración que va en contravía de los valores constitucionales. Es así que, mientras la Constitución Política anuncia el reconocimiento de la igualdad y la dignidad de cada cultura, la jurisprudencia ha dejado ver una evidente tendencia a hacer primar en cada caso los intereses y la visión moral del mundo propios de la cultura hegemónica.

Para concluir, si cabe, parece entonces indicarse que el reto permanece indemne en aquel país y, porque no decirlo, en países con tradiciones jurídicas de corte similar. En efecto, los ordenamientos jurídicos tradicionales parecen tener una evidente tendencia a fagocitar cuerpos culturales y morales que les resultan extraños, no pudiéndose aún procesar cosmovisiones sustantivamente diferentes de ver el mundo con resultados plenamente satisfactorios.

\section{Título de la Ponencia: "El fenómeno migratorio y la trata de personas"}

\section{Ponente: D. Alfredo Alpaca Pérez. Licenciado en Derecho por la Pontificia} Universidad Católica del Perú, Doctorando en Derecho Penal. Universidad de León

La migración es un fenómeno que acompaña al hombre prácticamente desde su origen. En efecto, es posible reconocer en la historia una serie de acontecimientos caracterizados por un amplio y continuo flujo o movimiento constante de personas de un lugar a otro. La posibilidad de que una persona se desplace de un lugar a otro ha sido incorporada al ámbito internacional de protección jurídica que se le confiere al individuo. Así, la Declaración Universal de los Derechos Humanos de 1948, en su artículo 13, establece no solo que "toda persona tiene derecho a circular libremente y a elegir su residencia en el territorio de un Estado", sino también que "Toda persona tiene derecho a salir de cualquier país, incluso del propio, y a regresar a su país". Independientemente de que este artículo genere una amplia discusión en la doctrina, referida a que tal disposición solo reconoce el derecho que tiene una persona a salir de su país (emigrar), pero no el derecho de entrar en otro (inmigrar), sobre las cuales, por el poco tiempo del que dispongo, no puedo referirme, queda claro que en el ámbito internacional existe la pretensión de otorgar una cobertura jurídica al individuo que de manera libre se desplaza de un lugar a otro. Ciertamente, ssegún las mencionadas normas internacionales, aunque existe un derecho de salida del propio país, nada se dice sobre un derecho de entrada a otro país, salvo en los casos en que se huya de persecución (política, étnica o religiosa), en los que resultará aplicable el derecho de asilo. Como es posible observar, a pesar de que en la legislación internacional se reconozca un "derecho a emigrar", se ignora su lógica contrapartida, a saber, un “derecho a inmigrar". Este derecho, a lo estar reconocido y menos aún recogido en 
algún instrumento internacional, no resulta vinculante para los potenciales Estados receptores.

Una persona puede decidir salir de su país de origen y llegar a otro por múltiples razones. Existen motivos económicos, políticos o sociales que hacen que una persona se desplace a otro lugar y fije en este su lugar de residencia. Precisamente, las condiciones de desigualdad económica y social en la que vive una persona en su lugar de origen pueden motivarlo a trasladarse a otro país, en el que pueda tener seguramente mayores posibilidades de un desarrollo económico o social. Pues bien, este escenario es aprovechado generalmente por organizaciones criminales de diversos alcances, orientadas la captación de personas para que, a través de ellas, o utilizándolas, se concreten una serie de actividades que pueden significar para aquellas entidades una innegable fuente de beneficios económicos.

Por ello, es posible decir que la trata de personas y la inmigración clandestina son fenómenos vinculados íntimamente con la inmigración. En lo que aquí importa, es posible decir que la trata de personas, aunque de ninguna manera se trata de un fenómeno nuevo, alcanzó relevancia en la política migratoria de los Estados europeos en la segunda mitad de los años noventa, cuando se evidenció un aumento del flujo migratorio ilícito proveniente de Europa del este, Latinoamérica, Medio Oriente, Asia y África, circunstancia en la que la criminalidad organizada internacional ostentó una importante participación. Asimismo, es importante destacar, como factor que acentuó la necesidad de abordar la trata de personas en el ámbito internacional, la gran atención que ha recibido por parte de los medios de comunicación lo relacionado a los fenómenos de los inmigrantes clandestinos y la trata de mujeres para fines de explotación sexual. La estrecha relación entre la trata de personas y la inmigración se evidencia al tomar en cuenta que la mayoría de víctimas de la trata de personas son extranjeros en el país en el que son identificadas como víctimas. Así, según el Reporte de la UNODC (Oficina de las Naciones Unidas para la Droga y el Delito) de 2014, de 10 víctimas del delito de trata de personas, como mínimo 6 son extranjeras (UNODC, Global Report on Trafficking in Persons 2014, New York, 2014, pp. 29 ss).

Entonces, ¿qué es la trata de personas? El Protocolo de las Naciones Unidas sobre Trata de personas (que complementa la Convención de las Naciones Unidas contra la Delincuencia Organizada Transnacional, y en el que, además, se abordó por primera vez el fenómeno de la trata de personas en el ámbito jurídico-internacional) señala, en su artículo 3, que hay tres elementos constitutivos de la trata de personas: el acto, los medios y el propósito. Estos tres elementos deben estar presentes para calificar un determinado caso como de trata de personas. El "acto" alude a la captación, el transporte, el traslado, la acogida o la recepción de personas. Los "medios" se refieren a la realización de los actos mencionados a través de la amenaza o el uso de la fuerza u otras formas de coacción, al rapto, al fraude, al engaño, al abuso de poder o de una situación de vulnerabilidad o a la concesión o recepción de pagos o beneficios para obtener el consentimiento de una persona que tenga autoridad sobre otra. Finalmente, el "propósito" implica la realización de todo lo anterior, teniendo el agente una finalidad de explotación. La explotación contempla a la explotación de la prostitución ajena u otras formas de explotación sexual, los trabajos o servicios forzados, la esclavitud o las prácticas análogas a la esclavitud, la servidumbre o la extracción de 
órganos. Según la definición empleada por el Protocolo, la comprensión que se ofrece sobre lo que es la trata de personas es bastante amplia, lo cual permite a los Estados parte del Protocolo una considerable discrecionalidad al momento de incorporar el delito de trata de personas en sus respectivos ordenamientos internos. Por ello, la regulación del delito de trata de personas puede poseer una configuración distinta de un país a otro.

Conociendo entonces los alcances, bastante amplios, de la definición de la trata de personas en el ámbito internacional, me encargaré ahora, para terminar, de exponer algunas ideas sobre la reforma del delito de trata de personas en el ordenamiento jurídico español, a partir de la última reforma del 2015. En España, el delito de trata de personas está tipificado en el artículo 177 bis del Código Penal español. Este delito había sido introducido en el Código Penal en la reforma producida por la Ley Orgánica $5 / 2010$, de 22 de junio. Por ello, es posible decir que el delito de trata de personas es relativamente joven en el ordenamiento jurídico nacional.

Las modificaciones introducidas se justifican, hasta donde entiendo, en la necesidad de una completa transposición de la Directiva 2011/36/UE, que a su vez se fundamenta en la necesidad de postular una perspectiva más orientada a las víctimas del delito. La Directiva 2011/36/UE permite entonces el traslado de una orientación criminocéntrica a una victimocéntrica, focalizada en los derechos humanos de las víctimas (IGLESIAS SKULJ, Agustina, «De la trata de seres humanos: artículo 177 bis CP», en: GonZÁlez Cussac, José Luis (Director), Comentarios a la Reforma del Código Penal de 2015, 2. ${ }^{a}$ edición, Valencia: Tirant lo Blanch, 2015, 595 ss). Dicho esto, los principales aspectos de la reforma del artículo 177 bis del Código Penal español son los siguientes:

1) En el ámbito de las conductas típicas, se suprime la conducta de "alojar", lo cual no resulta trascendente, pues el artículo 177 bis mantiene las conductas típicas de "recibir" o "acoger". La supresión de la conducta de "alojar" no parece tener una justificación lo suficientemente relevante. En todo caso, se puede decir que la supresión de la mencionada conducta responde al hecho de que esta no se haya prevista en el artículo 2.1 de la Directiva 2011/36/UE o el artículo 4 del Convenio del Consejo de Europa sobre la lucha contra la trata de seres humanos (Convenio de Varsovia) de 2005.

2) Se incluye la modalidad típica "o mediante la entrega o recepción de pagos o beneficios para lograr el consentimiento de la persona que poseyera el control sobre la víctima". Mediante esta inclusión, prevista en el artículo 2.1 de la Directiva 2011/36/UE, al parecer, se busca esclarecer supuestos específicos de trata de personas, como puede ser las actividades de venta, la permuta o alquiler de las víctimas (IGLESIAS SKULJ, Agustina, «De la trata de seres humanos: artículo 177 bis CP», op. cit., p. 597).

3) Se agregan como conductas típicas, el "intercambio o transferencia de control sobre esas personas". Esta incorporación proviene de lo dispuesto en el artículo 1 de la Directiva 2011/36/UE. El "intercambio" puede hacer referencia al cambio de personas por otras, o de personas por cosas (por ejemplo, drogas o armas) o por servicios. El "transferir" puede aludir a una cesión de una persona, mediante el pago de una determinada de dinero o sin él (QUERALT JiMÉNEZ, 
Joan, Derecho Penal Español. Parte Especial, Valencia: Tirant lo Blanch, 2015, 194).

4) Se suprime el término "trabajo forzado" y se mantiene solamente la referencia al "servicio forzado". La razón de esta supresión puede deberse, posiblemente, a la similitud entre ambos términos. Sin embargo, la supresión resulta problemática pues el Convenio 29 de la OIT reconoce expresamente y define el concepto de “trabajo forzado”. Por lo demás, esta supresión no parece ser acorde con la motivación general de la reforma, que como se dijo busca hacer posible una completa transposición de la Directiva 2011/36/UE, pues el "trabajo forzado" se encuentra reconocido de manera expresa en el artículo 2.1.3 de la mencionada directiva (IGLESIAS SKulJ, Agustina, «De la trata de seres humanos: artículo 177 bis CP», op. cit., p. 598).

5) Se incluye como nuevo supuesto de explotación a la "explotación para realizar actividades delictivas”. Este supuesto ya estaba contemplado en el artículo 2.3 de la Directiva 2011/36/UE. Por “actividades delictivas” habría que entender la realización de cualquier delito, aunque los más frecuentes sean los patrimoniales y de tráfico de drogas (QuERALt JimÉNEZ, Joan, Derecho Penal Español. Parte Especial, Valencia: Tirant lo Blanch, 2015, 196).

6) Se incluye como nuevo supuesto de explotación a la "celebración de matrimonios forzados”. Esta finalidad ya estaba contemplada en el considerando 11 de la Directiva 2011/36/UE, pero que, sin embargo, no la incluyó en el artículo 2.3 de la misma, en la que define las finalidades dentro del concepto de “explotación”. Esta incorporación puede generar problemas interpretativos (concúrsales) con el delito de matrimonio forzado, tipificado en el artículo 172 bis del Código Penal.

7) Se incluye una cláusula general (interpretativa) que dice "Existe una situación de necesidad o vulnerabilidad cuando la persona en cuestión no tiene otra alternativa, real o aceptable, que someterse al abuso". Con esta cláusula se pretende acabar con la indeterminación de conceptos como "situación de necesidad” o "vulnerabilidad”. La Directiva 2011/36/UE solo hace referencia a una "situación de vulnerabilidad” (IGLESIAS SKULJ, Agustina, «De la trata de seres humanos: artículo 177 bis CP», op. cit.., p. 599).

8) Se incluyen como tipos cualificados dos circunstancias: primero, el poner en peligro la vida o la integridad física o psíquica de las personas objeto del delito; y, segundo, que la víctima sea especialmente vulnerable por razón de enfermedad, estado gestacional, discapacidad, situación personal o sea menor de edad. Estas modificaciones cumplen de manera más detallada lo dispuesto en la Directiva 2011/36/UE.

Título de la Ponencia: "Trata de personas: Aspectos jurídicos penales en Colombia"

Ponente: Dña. Stephania Serrano Suárez. Doctoranda. Universidad de Salamanca

Colombia es un país de origen, tránsito y destino de trata de personas. Como causas de este fenómeno se evidencian, entre otras, la pobreza, la violencia hacia las mujeres, las altas tasas de desempleo y la ausencia de condiciones básicas para una vida digna. Este fenómeno se presenta con una agravación importante, como es la existencia de 
un conflicto armado interno que ha permanecido por décadas y que actualmente pretende ser finalizado mediante los diálogos de paz que mantiene el gobierno colombiano con las Fuerzas Armadas Revolucionarias de Colombia Ejército del Pueblo (FARC-EP). A pesar de evidenciarse esfuerzos para combatir la trata de personas, Colombia no cumple plenamente con las normas mínimas para eliminar este flagelo considerado como la esclavitud del siglo XXI. Así lo indica el Informe Mundial del Secretario General de los Estados Unidos (http://www.state.gov/ documents/organization/245365.pdf), que señala que Colombia se encuentra en el nivel 2 de lucha contra la trata de personas porque no cumple con los estándares mínimos del protocolo de Palermo. Lo mismo ocurre con la mayoría de países de la región latinoamericana, a excepción de Chile, que se ubica en el nivel 1.

La Convención de las Naciones Unidas para la Delincuencia Organizada y Transnacional, llamada también «Convención de Palermo», fue complementada con tres Protocolos («Protocolos de Palermo»): Protocolo de las Naciones Unidas para Prevenir, Reprimir y Sancionar la Trata de personas, especialmente mujeres y niños; Protocolo de las Naciones Unidas para el Contrabando de Migrantes por Tierra, Mar y Aire; y, Protocolo de las Naciones Unidas contra la fabricación y el tráfico ilícito de armas de fuego. El artículo 3 del Protocolo de Palermo para Prevenir, Suprimir y Castigar la Trata de Personas, especialmente la de mujeres y niños, del año 2000, estableció que la trata de personas, como fenómeno criminal, contemplaba la captación, el transporte, el traslado, la acogida o la recepción de personas, recurriendo a la amenaza o al uso de la fuerza u otras formas de coacción, al rapto, al fraude, al engaño, al abuso de poder o de una situación de vulnerabilidad o de la concesión o recepción de pagos o beneficios para obtener el consentimiento de una persona que tenga autoridad sobre otra, con fines de explotación. La explotación incluirá, como mínimo, la explotación de la prostitución ajena u otras formas de explotación sexual, trabajos o servicios forzados, esclavitud o prácticas similares, servidumbre o extracción de órganos.

En efecto, la trata de personas, implica tres elementos fundamentales: la actividad, los medios y la finalidad. Respecto a la actividad, ha de decirse que el tipo penal de trata de personas que se encuentra tipificado en el artículo 188A del Código Penal Colombiano en su estructura contempla, como primera conducta típica, la conducta de «captar», que presupone el reclutamiento de la víctima o atraerla para controlar su voluntad para fines de explotación. Con respecto a la conducta de «trasladar», recogida en el delito tipificado, es importante mencionar que en la regulación internacional se han establecido los comportamientos consistentes en «trasportar»y «trasladar». Sin embargo, la figura delictiva reconocida en la legislación penal colombiana solo alude al verbo rector «trasladar». Este comportamiento, según la DRAE, alude al «llevar a alguien o algo de un lugar a otro». Con respecto a «acoger» o «recibir» -también señalados, como vimos, de manera expresa en el artículo 3 del Protocolo de Palermo-, se afirma que se tratan de términos homologables. Sin embargo, en la doctrina jurídico-penal se ha planteado algún criterio que permite establecer una diferenciación (aunque sea muy tenue) entre las mencionadas conductas: mientras el «recibir» puede definirse como la admisión física de la víctima, el «acoger» puede suponer el mantener a la víctima en un lugar seguro. Respecto a los medios utilizados para la comisión de este delito, se resaltan el engaño, el fraude, la 
coerción entre otros, y sobre la finalidad, no existe duda de que debe ser la explotación de un ser humano. Del tipo en cuestión, ha de decirse que es de conductas alternativas, mutilado de dos actos y con tendencia interna trascendente. En relación a las modalidades en las que este delito se aplica, ha de tenerse lo preceptuado por el Protocolo de Palermo. Así, se puede configurar este delito en los siguientes supuestos: Explotación sexual, trabajos o servicios forzados, matrimonio servil, esclavitud o prácticas análogas a la esclavitud, mendicidad ajena y explotación de órganos (Vid. Villacampa Estiarte, C., El Delito de Trata de Seres Humanos. Una incriminación dictada por el Derecho Internacional, Cizur Menor (Navarra), Thompson ReutersAranzadi, 2011; Iglesias Skulj, A., La trata de mujeres con fines de explotación sexual: una aproximación político criminal y de género, Buenos Aires, Didot, 2013).

La trata de personas puede presentarse de forma externa o interna. Se considera que aquella es externa si el proceso tiene lugar en territorios de diversos países, mientras que la interna se presenta dentro de las fronteras de un mismo país. La trata de personas externa con fines de explotación sexual genera altísimos ingresos, especialmente en los lugares turísticos de la zona costera colombiana. De igual forma, cobra gran importancia en este país la trata de personas interna en dos situaciones particulares: el reclutamiento forzado y la explotación de menores. El reclutamiento forzado se presenta como fenómeno directamente relacionado al conflicto armado, el cual presenta un proceso de externalización de los impactos, esto quiere decir, que afecta directa y crecientemente a la población civil. Esta situación dio lugar a que en el artículo 162 del Código Penal Colombiano se tipificara el comportamiento de reclutamiento ilícito, conforme a la normativa del Derecho Internacional de los Derechos Humanos, el Derecho Internacional Humanitario y el Derecho Penal Internacional (Vid. Corte Constitucional Colombiana C-240 de 2009. Magistrado Ponente: Mauricio González Cuervo). En principio, la conducta reprochada en este tipo se considera trata de personas puesto que el reclutamiento ilícito implica captación, traslado, acogida y recepción, y además, tiene como finalidad la explotación que se exige para la configuración del delito de trata de personas. No obstante, la razón de ser de este tipo penal, es su especialidad, debido a que los sujetos pasivos del delito son los niños, niñas y adolescentes, aunado a que la conducta requiere ser ejecutada en el contexto específico del conflicto armado. Razones por las cuales cuando se presenta un reclutamiento por parte de los grupos armados al margen de la ley, cuyas víctimas sean mayores de edad, se aplicará el delito de trata de personas. En caso contrario, se aplicará lo dispuesto por el artículo 162 del Código Penal Colombiano.

Por otra parte, la reciente jurisprudencia colombiana señala que la explotación de menores y la trata de personas son delitos autónomos. A pesar de lo cual, considero que la tipificación del delito de explotación de menores en el Código Penal Colombiano es deficiente y genera problemas de índole constitucional en la medida en que, el delito que se debe aplicar en los casos en que un individuo utiliza coactivamente a menores de edad para mendigar o pedir limosnas es el delito de trata de personas, entre otras cosas, porque la mendicidad ajena como finalidad se encuentra contenida en el tipo de trata de personas, y en este caso, a diferencia de lo referido anteriormente sobre el delito de reclutamiento ilícito, no es dable aplicar el principio de especialidad del tipo. La relación existente entre el delito de trata de 
personas y el delito de explotación de menores es la de un concurso aparente de leyes, que debe resolverse mediante la aplicación del principio de consunción. Esto quiere decir que, en la medida que el delito de trata de personas incluye el desvalor del delito de explotación de menores, el concurso aparente de leyes existente entre ambas figuras delictivas debe resolverse a favor de la aplicación de la primera de ellas (Sobre el principio de consunción como elemento para la resolución de casos de concurso aparente de leyes (Vid., por todos, Mir Puig, S., Derecho Penal. Parte General, 9. edición, Barcelona, Reppertor, 2011). De modo que no se comparte la conclusión de la Corte Constitucional Colombiana que, al admitir la diferenciación de los ámbitos de proyección de los delitos de trata de personas y de explotación de menores, afirma que entre estas figuras delictivas no existe una «identidad típica». En ese sentido, debe entenderse que el delito de explotación de menores se encuentra subsumido totalmente en el delito de trata de personas (Vid. Corte Constitucional Colombiana C-464 de 2014 Magistrado Ponente: Alberto Rojas Ríos).

Como colofón, la Directora del Seminario, Dña. Aurelia Álvarez, junto con la Secretaria de la Facultad de Derecho, Dña. Isabel Durán en representación del Sr. Decano, procedieron al acto de clausura, en la que se puso de manifiesto que en el desarrollo del III Seminario se ha podido llevar a cabo un análisis de la panorámica de la integración de extranjeros desde variados ámbitos del Derecho, comprobando así que las diferentes ramas del Derecho presentan conexiones sumamente interesantes.

\section{ACTIVIDADES REALIZADAS EN EL CURSO DE VERANO TITULADO "STATUS JURÍDICO DE LOS EXTRANJEROS EN LA UE Y SU IMPLICACIÓN EN LAS POLÍTICAS DE INTEGRACIÓN” $Y$ EN EL SENO DEL IV SEMINARIO SOBRE RELACIONES JURÍDICAS INTERNACIONALES: AVANCES Y RETROCESOS EN LA POLÍTICA MIGRATORIA EUROPEA}

Durante el año 2016, debemos resaltar la visualización de dos eventos que tuvieron lugar en el mes de septiembre de 2016 en la Universidad de León: el Curso de Verano titulado "Status jurídico de los extranjeros en la UE y su implicación en las políticas de integración, ¿realidad o ficción?, del 19 al 22 de septiembre y el IV Seminario sobre Relaciones Jurídicas Internacionales: Avances y retrocesos en la política migratoria europea, impartido en la Facultad de Derecho de la Universidad de León los días 27 y 28 de septiembre.

En ambas reuniones se pretendía dar a conocer una visión general de la política migratoria europea y española desde una perspectiva multidisciplinar de carácter teórico-práctica. Entre sus objetivos fundamentales destacan dos aspectos: distinguir claramente los diferentes regímenes normativos según el colectivo y el origen de las disposiciones legales; además de divulgar no solo las normas sino también la interpretación de las mismas: analizando la jurisprudencia más relevante. 
En el primero de los eventos se plantearon debates sobre los siguientes temas: la gestión de la frontera exterior UE y la respuesta europea a la actual crisis de los refugiados; las situaciones de irregularidad administrativa en cuanto a las detenciones, el internamiento y las expulsiones; la protección de los colectivos más vulnerables tales como menores extranjeros no acompañados y mujeres; la integración de los inmigrantes en la sociedad española desde las perspectiva social, laboral y penal; y, finalmente, la materia de la nacionalidad española en relación a su adquisición (nuevos procedimientos) y la libre circulación de personas en el espacio europeo de los familiares no comunitarios de los nuevos nacionales. Para llevar a cabo esta actividad contamos con los siguientes ponentes y participantes: Dra. Elena Arce Jiménez, Abogada y Asesora del Defensor del Pueblo de España; Dra. Susana Cuadrón Ambite, Abogada del ICAM y Tutora UNED; Dra. Isabel Duran Seco, Profesora Contratada Doctora de Derecho Penal ULE; Dña. Paloma Favieres Ruiz, Abogada de la Comisión Española de Ayuda al Refugiado (CEAR); Dr. Roberto Fernández Fernández, TU de Derecho del Trabajo y la Seguridad Social ULE; D. Rafael Martínez Fernández, Jurista del Cuerpo Superior de Técnicos de Instituciones Penitenciarias; Dr. Jacobo Muñoz Comet, Profesor de Sociología UNED; Dr. Paulino Cesar Pardo Prieto, TU de Derecho Eclesiástico del Estado ULE; Dr. José Miguel Sánchez Tomás, Letrado del Tribunal Constitucional y TU Derecho Penal. Rey Juan Carlos de Madrid; Dr. Salvador Tarodo Soria, TU de Derecho Eclesiástico del Estado ULE; Dra. María Anunciación Trapero Barreales, TU, acreditada Catedrática, de Derecho Penal ULE; y la Dra. Marina Vargas Gómez-Urrutia, TU de Derecho internacional privado UNED.

En el IV Seminario sobre Relaciones Jurídicas Internacionales centró su atención en los “Avances y retrocesos en la política migratoria de la UE". En la primera ponencia el Dr. Andrés Rodríguez Benot, Catedrático de Derecho internacional privado de la Universidad Pablo de Olavide, delimitó el marco regulador general a nivel comunitario en torno al Derecho de Familia internacional, tales como, régimen económico matrimonial, divorcio, sucesiones, parejas de hecho, etc. Incidió en los trabajos que la Comisión Europea está realizando en el Reglamento (CE) 2201/2003 en materia de disolución del matrimonio y responsabilidad parental. A continuación se desarrolló la mesa redonda con aspectos interdisciplinares en torno al Derecho migratorio actual. Se trataron cuestiones acerca de la problemática actual que supone la no atención sanitaria a los inmigrantes que carecen de residencia legal y la imposibilidad de acceso a las diversas prestaciones de Seguridad Social del colectivo extranjero irregular. Además también se abordó el pluralismo cultural en el ámbito sanitario sin olvidar que el derecho a la salud presenta protección constitucional en nuestro Estado. En la sesión de tarde, el Dr. Dionisio Llamazares, dedicó sus minutos de conferencia a incidir en la importancia que supone la tolerancia y el diálogo efectivo en el marco de la sociedad plural y multicultural que está inmerso España. Finalmente, y como cierre de la jornada del martes 27, se constituyó una mesa redonda en la que se aludió a la protección jurídica de colectivos vulnerables; en concreto, extranjeros privados de libertad con especial atención a la prisión de Villahierro, los refugiados a la luz del Acuerdo UE-Turquía y su fracaso en el amparo a los asilados, y las mujeres inmigrantes en el escenario de las familias monoparentales. Al día siguiente, se comenzó el acto con la ponencia del Dr. Javier García Medina, Director del Observatorio de Derechos Humanos de la Universidad de Valladolid. Situó a todo 
el aforo asistente en una cruda realidad: la trata de seres humanos, en la que se resaltó sus causas, consecuencias y la fuerte problemática en la que están inmersas las víctimas. Seguidamente, tuvo lugar la mesa redonda conducida al análisis de la Ciudadanía europea, Brexit e identidad territorial. Se destacaron asuntos de los eventuales perjuicios y beneficios de la salida de Reino Unido de la UE, no sólo desde la óptica jurídica sino también económica. También han realizado su especial contribución en este IV Seminario los siguientes comunicantes: Dña. Nieves Alonso García, Doctoranda en Derecho Constitucional ULE; Dña. Tamara Álvarez Robles, Doctoranda en Derecho Constitucional ULE; Dña. Natalia Cañiz García, Asesora Jurídica de ACCEM CyL; Dr. Roberto Fernández Fernández, TU de Derecho del Trabajo y la Seguridad Social ULE; Dña. María García Álvarez. Fundadora y Presidenta de la Fundación de Familias Monoparentales Isadora Duncan; Dra. Nuria González Rabanal, Decana del Ilustre Colegio de Economistas de León y Profesora de la Facultad de CC.EE. y Empresariales ULE; D. Rafael Martínez Fernández, Jurista del Cuerpo Superior de Técnicos de Instituciones Penitenciarias; Dr. Paulino Cesar Pardo Prieto, TU de Derecho Eclesiástico del Estado ULE; Dr. Salvador Tarodo Soria, TU de Derecho Eclesiástico del Estado ULE.

Por otra parte, algunas de la intervenciones orales tanto del IV Seminario como del Curso de Verano han sido reflejadas por escrito y han sido objeto de publicación en el número monográfico de la Revista "Unión Europea Aranzadi", núm. 2, febrero 2017 bajo el título "Inmigración en la UE: Pocas luces y muchas nubes negras", dirigido por Aurelia Álvarez Rodríguez y coordinado por D. David Carrizo Aguado. Los autores y trabajos que integran el volumen mencionado son los siguientes: Nieves Alonso García, "La asistencia sanitaria a los extranjeros en situación irregular a la luz de la STC 139/2016, de 21 de julio de 2016: Universalidad vs. Gratuidad"; Tamara Álvarez Robles, "Las identidades nacionales en la configuración de la Ciudadanía Europea"; Aurelia Álvarez Rodríguez y David Carrizo Aguado: "El fenómeno migratorio en el contexto de la Unión Europea: el silencio ensordecedor que apaga el grito de los más vulnerables"; Natalia Cañiz García, "Sistema Europeo Común de Asilo bajo el Acuerdo UE-Turquía: ¿Refugiados sin ley?”; Susana Cuadrón Ambite, "La Directiva de retorno y su interpretación a la luz de la Sentencia del Tribunal de Justicia de la UE de 23 de abril del 2015"; Roberto Fernández Fernández, "La protección laboral de los trabajadores extranjeros en situación irregular: criterios jurisprudenciales en torno al salario y los despidos"; Javier García Medina, "Trata de seres humanos: la vulnerabilidad de sus víctimas"; Paulino Cesar Pardo Prieto, "Tensión entre identidad y pluralidad: Inmigración en Malta"; María Anunciación Trapero Barreales, "La reforma de 2015 en el Derecho penal de extranjeros: la tipificación del delito de matrimonio forzado (siguiendo el modelo de los países de la Unión Europea), ¿una nueva manifestación del uso simbólico del Derecho penal?”; y Marina Vargas Gómez-Urrutia, "Reflejos de la idea de integración en las normas de extranjería y de nacionalidad. Especial referencia al nacido en España hijo de extranjeros".

Para concluir, debemos poner de manifiesto que todo ello no hubiese sido posible sin la labor realizada por todos los profesores e investigadores que forman parte del Grupo ULE de Innovación Docente "Inmigración, Nacionalidad e Interculturalidad" y del Grupo de Investigación Relativo a la Regulación de los Flujos Migratorios 
(INNAIN/GID-INI) junto con el Grupo de Investigación: Extranjería y Migración UNED. Ello, sin olvidar, la inmensa deuda contraída con la Dra. Marina Vargas Gómez-Urrutia, codirectora del Curso de Verano por su admirable trabajo e intensa colaboración, sin la cual no hubiese sido posible lograr el éxito obtenido en el desarrollo del mismo.

En todo caso, cabe reseñar que las actividades descritas pueden consultarse en los materiales audiovisuales editados por la ULE: I Seminario sobre relaciones jurídicas internacionales: familia e interculturalidad (https:/videos.unileon.es/es/serial/ 95.html); II Seminario sobre relaciones jurídicas internacionales: Inmigración Educación e Interculturalidad (https:/videos.unileon.es/es/serial/132.html); III Seminario sobre relaciones jurídicas internacionales: El reto de la integración de los inmigrantes y su repercusión en la UE (https://videos.unileon.es/es/serial/154.html); IV Seminario sobre relaciones jurídicas internacionales: Avances y retrocesos en la política migratoria de la Unión Europea (https://videos.unileon.es/es/serial/189.html); Curso de Verano: Status jurídico de los extranjeros en la UE y su implicación en las políticas de integración, ¿realidad o ficción? (https://videos.unileon.es/es/serial/ 187.html). 